\title{
Artifact suppression of SSFP cine sequences at 3T using a novel automatic 3D shimming algorithm
}

\author{
Tamara Rothstein ${ }^{1 *}$, Gabriel C Camargo ${ }^{1}$, Daniel C Quintella ${ }^{1}$, Elsa Fernandes ${ }^{1}$, Ralph Strecker ${ }^{2}$, Andreas Greiser ${ }^{3}$, \\ Maria Eduarda Derenne ${ }^{1}$, Marceu Lima', Joao J Moojen', Patricia B Rizzi ${ }^{1}$, Ronaldo SL Lima', Ilan Gottlieb
}

From 16th Annual SCMR Scientific Sessions

San Francisco, CA, USA. 31 January - 3 February 2013

\section{Background}

Imaging the heart at 3T has some advantages, but magnetic susceptibility increases at higher field strengths, generating deleterious banding artifacts, especially when using SSFP-based sequence. We aimed to evaluate whether a recently developed advanced shimming algorithm reduces banding artifacts on SSFP cine images at 3T.

\section{Methods}

A total of 20 consecutive patients scheduled to undergo a clinically indicated CMR in normal sinus rhythm and able to perform apnea were prospectively enrolled to be scanned in a 3T system (MAGNETOM Verio, Siemens, Germany). Frequency scout images were acquired in two and four chamber views and the frequency offset associated with least banding artifacts involving the heart was manually set (Figure 1) for the acquisition of short and long axis segmented cine SSFP images covering the entire ventricular volumes (bandwidth of $700-750 \mathrm{~Hz} /$ pixel and echo spacing of $3.4 \mathrm{~ms}$ ). The same sequences were then repeated with the offset reset to $0 \mathrm{~Hz}$ (only change made) but with the use of a novel 3D shimming algorithm restricted to the heart (instead of the entire FOV) based on a patient specific GRE fieldmap previously generated (WIP - Siemens, Germany).

Images were blindly evaluated for segmental function (normal vs. abnormal), and the presence of artifacts within the heart (none, minor or important - the latter meaning that at least one myocardial segment could not be assessed). Ventricular volumes were also blindly mea-

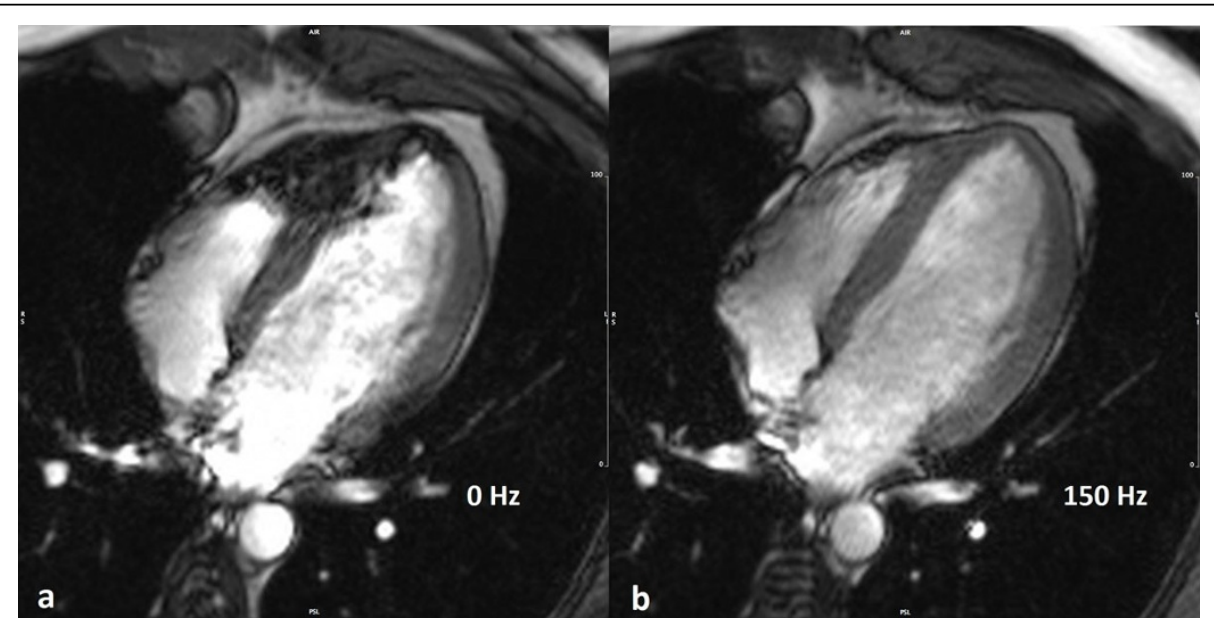

Figure 1 Frequency scout images of the four chamber view. Banding artifacts are seen at frequency offset of $0 \mathrm{~Hz}$ (a), but not at $150 \mathrm{~Hz}$ (b).

${ }^{1}$ CDPI - Clínica de Diagnóstico por Imagem, Rio de Janeiro, Brazil

Full list of author information is available at the end of the article

(c) 2013 Rothstein et al; licensee BioMed Central Ltd. This is an Open Access article distributed under the terms of the Creative 
Table 1 Mean LV and RV volumes and ejection fraction.

\begin{tabular}{ccccc}
\hline & with shim & without shim & p-value & bias* $^{*}$ \\
\hline LVEDV & 139,0 & 133,5 & 0,67 & 5,5 \\
LVESV & 60,0 & 60,1 & 0,99 & $-0,1$ \\
LVEF & $59,5 \%$ & $59,0 \%$ & 0,91 & $0,5 \%$ \\
RVEDV & 127,5 & 124,6 & 0,77 & 2,9 \\
RVESV & 60,0 & 57,5 & 0,70 & 2,5 \\
RVEF & $53,7 \%$ & $55,0 \%$ & 0,57 & $-1,3 \%$ \\
\hline
\end{tabular}

* with shim - without shim

sured according to guidelines. Categorical differences were assessed with chi-square, kappa was calculated for agreement and continuous variables were assessed using Student's T test.

\section{Results}

Mean LV and RV volumes and ejection fraction (EF) were not statistically different between acquisition modes, and had small biases between measurements (Table 1). Segmental wall motion analysis had good agreement with kappa of $0.76, \mathrm{p}<0.001$. Minor artifacts were seen in at least one segment in $4(20 \%)$ patients using the new shimming and 7 (35\%) using frequency offsets. Important artifacts were seen in at least one segment in $3(15 \%)$ patients using the new shimming and 2 (10\%) using frequency offsets.

\section{Conclusions}

Cine SSFP at 3T with a new shimming algorithm targeted to the heart is similar to the standard practice of selecting the best frequency offset. This new shimming might simplify cardiac acquisitions at 3T.

\section{Funding}

Internal

Author details

${ }^{1}$ CDPI - Clínica de Diagnóstico por Imagem, Rio de Janeiro, Brazil. ${ }^{2}$ Siemens

Ltda, São Paulo, Brazil. '3Siemens Healthcare, Erlangen, Germany.

Published: 30 January 2013

doi:10.1186/1532-429X-15-S1-P57

Cite this article as: Rothstein et al:: Artifact suppression of SSFP cine sequences at 3T using a novel automatic 3D shimming algorithm. Journal of Cardiovascular Magnetic Resonance 2013 15(Suppl 1):P57.
Submit your next manuscript to BioMed Central and take full advantage of:

- Convenient online submission

- Thorough peer review

- No space constraints or color figure charges

- Immediate publication on acceptance

- Inclusion in PubMed, CAS, Scopus and Google Scholar

- Research which is freely available for redistribution

Submit your manuscript at www.biomedcentral.com/submit
C Biomed Central 